\title{
Soil and Land Suitability Assessment for Rice Cultivation at Tono Irrigation Area in the Upper East Region, Ghana
}

\author{
Prince M. Gyekye ${ }^{1 *}$, Charles Y. F. Domozoro², Mohammed Musah ${ }^{3}$, Felix O. Ababio ${ }^{4}$, \\ Adams Sadick ${ }^{5}$
}

${ }^{1}$ Soil Survey, GIS and Mapping, CSIR-Soil Research Institute, Accra, Ghana

${ }^{2}$ Natural Resources Management, CSIR-Animal Research Institute, Accra, Ghana

${ }^{3}$ Soil Fertility and Nutrition, CSIR-Soil Research Institute, Kwadaso, Ghana

${ }^{4}$ Directorate/Soil Fertility, CSIR-Soil Research Institute, Accra, Ghana

${ }^{5}$ Analytical Services Laboratory, CSIR-Soil Research Institute, Kwadaso, Ghana

Email: *sadickadams1971@gmail.com

How to cite this paper: Gyekye, P.M., Domozoro, C.Y.F., Musah, M., Ababio, F.O. and Sadick, A. (2021) Soil and Land Suitability Assessment for Rice Cultivation at Tono Irrigation Area in the Upper East Region, Ghana. Open Journal of Applied Sciences, 11, 1230-1239.

https://doi.org/10.4236/ojapps.2021.1111093

Received: October 24, 2021

Accepted: November 26, 2021

Published: November 29, 2021

Copyright $\odot 2021$ by author(s) and Scientific Research Publishing Inc. This work is licensed under the Creative Commons Attribution International License (CC BY 4.0).

http://creativecommons.org/licenses/by/4.0/

\begin{abstract}
Agriculture is one of the livelihood supports for the people of Upper East Region of Ghana. Soil evaluation research was conducted at Tono Irrigation Scheme to assess soil and land suitability for rice cultivation in the irrigable area of Tono Irrigation Scheme. A total of eleven (11) soil samples were collected and analysed for their chemical and physical properties. Based on field observation and criteria for soil suitability assessment, the different soil types that were identified were classified at the series level based on their position, parent material and the observed physical characteristics. The results indicated that the $\mathrm{pH}$ of the soils was within the acceptable range for crop production; however, the overall fertility level of the soils was very low. Physically, the upland soils were well to moderately well-drained, consisting of coarse-grained sandy loams topsoil overlying similar sandy loams and sandy clay loams at depth. They included Leptosols and Lixisols. The soils of the Scheme under lowlands and valley bottom sites, however, included Eutric Gleysol, Calsic Vertisol, Eutric Fluvisol and Eutric Plinthosol, which were heavily textured and relatively poor drained, or medium-textured and moderately to imperfectly well-drained. They showed a low to a very low rate of water percolation losses, which is good for the current farming system of cropping rice within the lowlands and valley bottom sites of the Scheme.
\end{abstract}

\section{Keywords}

Soil Classification, Lowland, Upland, Irrigation, Valley Bottom 


\section{Introduction}

The erratic nature of the rainfall pattern, coupled with long periods of drought renders agriculture a risky business in Ghana. Besides, population growth with its subsequent settlement expansion has led to a higher demand for land acquisition for the production of food crops such as rice and maize, among others [1]. The Upper East Region is notable for high levels of environmental degradation, deforestation and loss of soil cover, stemming from extremely high population densities of both humans and livestock, not accompanied by agricultural development [2]-[8]. Again, the low fertility levels of most Ghanaian soils and the poor performance of the agricultural sector are due partly to the over-reliance on rainfall as the main source of water supply for crop growth. Under these prevailing climatic conditions, the country's agriculture cannot sustain the growing population without the promotion of extensive and intensive irrigation and effective soil management [9]. To make an adequate and strategic plan towards sustaining the food needs of the country's growing population, serious attention is required in the area of the country's agricultural sector for major crops that the agroecology supports [10]. Also, matching land qualities to land-use requirements will allow farmers to maximize agricultural production outputs while also helping them to effectively manage their lands.

Nitrogen, Phosphorus, Potassium, Calcium, Magnesium, and Manganese were recognized as key elements in rice production by [11]. In the same vein, [12] established land categories to designate areas appropriate for the growth of certain crops. Thus, land suitability studies assist in determining soils for optimal crop yields.

The Tono dam, one of West Africa's largest agricultural dams, is mostly utilized for irrigated farming, especially during the dry season when rainfall is scarce [13]. Although the dam has an estimated capacity of $92.6 \mathrm{mill} \mathrm{m}^{3}$ following its construction in 1979, its water volume in the dam has decreased significantly over the years, according to [13]. To preserve this viable facility, the underlying soils of the dam need to be critically studied and the suitability of the soils puts to proper use to ensure food security.

Soil survey and land suitability assessments are critical prerequisites for any successful agriculture or forestry project. Hence, information on soil qualities and conditions in the Tono dam area, as well as the soil's fertility status, is required to determine the physico-chemical properties of the soil for rice cultivation. The necessity for such knowledge is the research's problem [1]. The frequency of failed agricultural or forestry projects where diligent soil assessments are not carried out demonstrates the importance of soil and land assessments and the dangers of disregarding land suitability constraints. Land suitability assessment involves the analysis of soil and landscape information as well as climate information of a given area to determine the suitability of the area for the production of specified crops under rain-fed or irrigated farming. Much research has been done on the Tono irrigation scheme, but unfortunately, research on soil classification and soil series for land suitability assessment is lacking. 
This research, therefore, seeks to identify soil quality requirements for rice cultivation at different soils occurring in the target development block and to classify them into individual soil types. Information obtained from such research will help in formulating meaningful guidelines in ensuring the sustainability of agricultural practice as well as rice cultivation in the Tono Irrigation Scheme as well as the Guinea Savanna Agroecological Zone.

\section{Materials and Methods}

The land is located $3 \mathrm{~km}$ South-West of Navrongo, with the Navrongo-Sandema road passing through it at the very top. It lies within longitudes $1^{\circ} 4^{\prime} \mathrm{W}$ and $1^{\circ} 10^{\prime} \mathrm{W}$, and latitudes $10^{\circ} 44^{\prime} \mathrm{N}$ and $10^{\circ} 54^{\prime} \mathrm{N}$. The total area covered by the survey was approximately 3390 hectares (Figure 1 ).

The project area is made up of eight (8) command areas: Bonia, Gaani, Korania, Wuru, Yigania, Yigwania, and Chuchuliga zone A and B. The total annual rainfall in the area is between around 950 and $1200 \mathrm{~mm}$ which normally stars in May, reach a peak in August then drop sharply in October. After that, there is a long dry period from November to the end of April in which only negligible amounts of rain are received [14].

Average monthly temperatures remain high throughout the year only falling around $26^{\circ} \mathrm{C}$ in August and September at Navrongo. March and April are the hottest months recording nearly $32^{\circ} \mathrm{C}$. Absolute minimum temperatures of around $16^{\circ} \mathrm{C}$ are usually recorded in December or January with an absolute maximum temperature of about $35^{\circ} \mathrm{C}$ recorded in March and April [14].

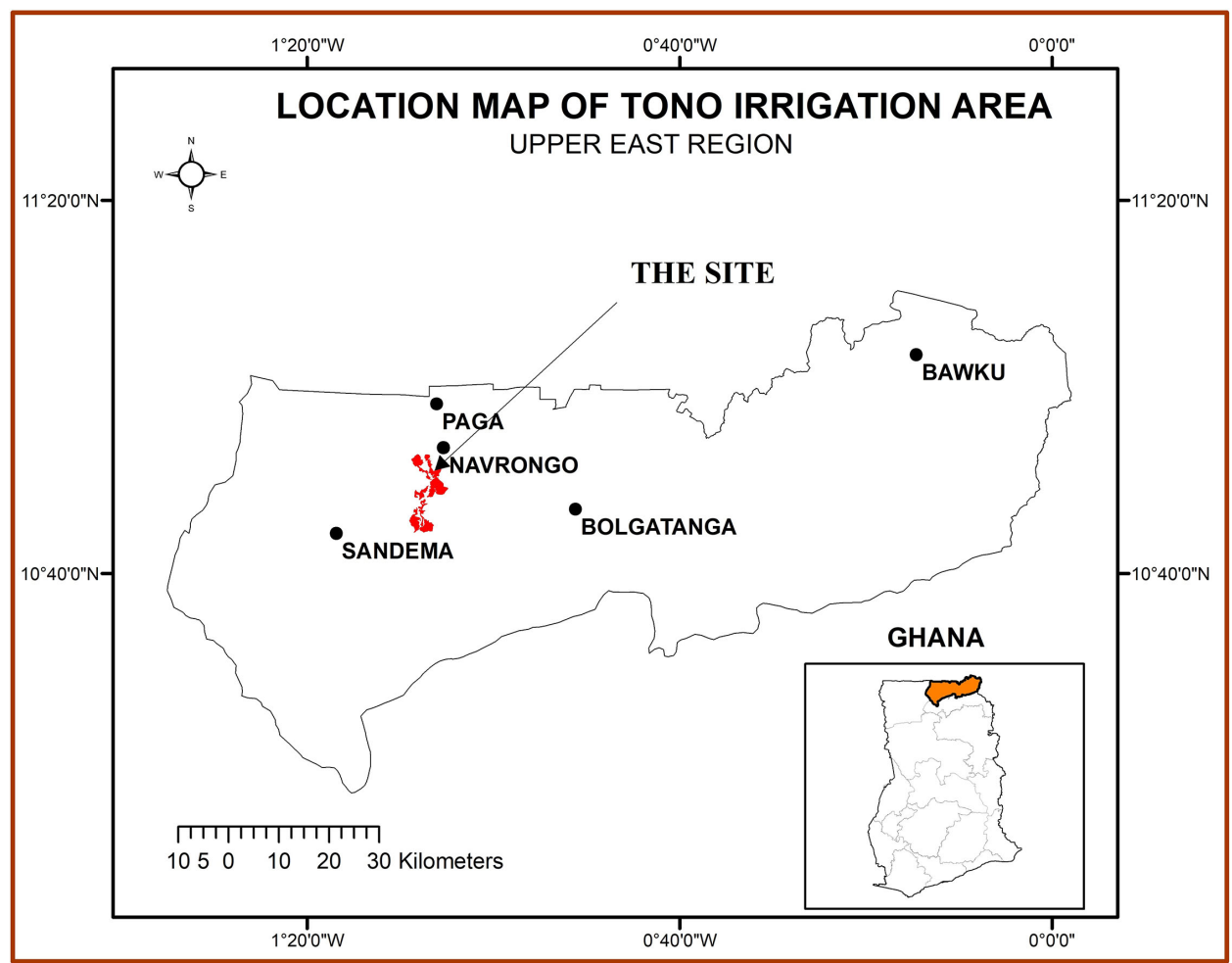

Figure 1. Location of tono irrigation scheme [14]. 
Relative humidity percent for the study area remains high during the wet season in particular, between July and September, and low in the dry harmattan period within January and February. Data indicate low diurnal and monthly humidity readings between noon and 1500 hours and high diurnal humidity readings between midnight and 0600 hours. Usually, humidity during the noon to 1500 hours period maybe 20 to 30 percent lower than at 0900 hours [14].

The method used in this research involved field identification, soil sampling and soil analysis in the laboratory.

\subsection{Field Survey}

Field soil examination was carried out according to the grid method, guided by findings of previous soil surveys by [3] [15] and soil map of the Tono irrigation project, produced by the staff of the Soil Division of the Ghana Irrigation Development Authority.

Before the commencement of the fieldwork, a Google image of the Tono Project site was downloaded and used as the base map. A quick reconnaissance was performed in the field to pick some controlled points using handheld GPS. This was followed by desk-top studies in which the controlled points were transferred unto the base map to geo-reference it. The map was then projected and exported to an ArcGIS environment for further processing.

Parallel traverse lines at $400 \mathrm{~m}$ intervals measuring various lengths and totaling 74 were constructed on the map. This was to enable a grid survey of $100 \mathrm{~m} \times$ $400 \mathrm{~m}$ (auger density of 1 per 2 ha) to be carried out.

The field survey, therefore, involved a $100 \mathrm{~m}$ interval soil observation on all the traverse lines. However, where there were breaks of slopes or depressions, soil observations were carried out at a relatively short interval. The landscape was categorized into two aerial units: Upland soils made up of soils on the summit, upper and middle slope sites and lowland soils made up of lower slope and valley bottom soils.

Soil observation involved auguring to a depth of approximately $100 \mathrm{~cm}$ or the impenetrable layer, describing the soil characteristics, including texture, colour, presence of concretions, stones and gravel, position on the landscape and finally geo-referencing the points with a GPS. The soils were tentatively classified to their series level [3], pending confirmation after correlation.

Eleven profile pits representing the most extensive soils were dug and described according to "Field book for describing and sampling soils" [16], after which samples were taken at each genetic horizon for laboratory analysis. The GPS points were transferred to the base map and with additional information obtained from the field, the soil boundaries were redrawn.

\subsection{Laboratory Analysis}

Soil samples collected from the eleven soil pits together with the auger samples were sent to the laboratory for analysis. The soil samples were air-dried to con- 
stant weight to avoid microbial degradation [17], crushed and sieved to retain the $<2 \mathrm{~mm}$ material for analysis. The physicochemical properties of the soil samples were determined using routine methods adopted and described by [18] and [19].

\section{Soil Classification}

Based on the field observations, and soil analysis, the different soil types that were identified were classified at the series level based on their position, parent material and the observed physical characteristics as reported in the Soils of the Navrongo-Bawku area, and the Vol. III report on Land and Water Surveys in the Upper and Northern regions.

The upland soils of the Tono Irrigation Scheme area were either concretionary (Tanchera and Puga series) in the subsoil or were free from any concretions (Sirru, Varampere). Seepage ironpan was encountered within $30 \mathrm{~cm}$ at depth (Wenchi and Gulo series) or below $70 \mathrm{~cm}$ (Tafali series). Shallow Kolingu series occurred on 2 - 3 per cent slopes and was easily distinguished by the presence of quartz gravel and stones which frequently littered the ground surface. The shallow soils of the lowland portions, however, included poorly drained and eroded Leptosols ( $P u$ series). The medium textured soils of the lowlands, which were also free from concretions included the Berenyasi and Dagare series, whiles the deep and lighted textured soils were made up of the Kunkwa series. The poorly-drained alluvia heavy textured soils (Siare, Kupela and Pani series) occupied the lowland to valley bottom slope areas of the study site.

Finally, the soil series were correlated to the Food and Agricultural Organization [20] soil legend.

\section{Soil Suitability Assessment for Irrigation}

The criteria for soil suitability assessment for irrigation were based on Guidelines: Land Evaluation for Irrigated Agriculture, an FAO soils bulletin No.55. The assessment followed 17 step-by-step guidelines for consideration to obtain a suitability assessment for irrigation. It took into consideration limitations for specifications of land use requirements, land qualities and land characteristics and factor ratings to match a land utilization type and a land unit.

The FAO land suitability classification system has four levels, which reflect the details of suitability for specific uses. They are presented as follows:

$I$ - Land suitability orders There are two orders, namely: Suitable (S) and Non-Suitable (N).

II - Land suitability classes This level consists of five main classes which indicate the degree of suitability within the suitability orders, which include;

(Suitable-S):

1) $\mathrm{S} 1=$ high: $80 \%-100 \%$ of maximum attainable yield

2) $\mathrm{S} 2=$ moderate: $60 \%-80 \%$ of maximum attainable yield

3) $\mathrm{S} 3=$ marginal: $40 \%-60 \%$ of maximum attainable yield 
(Not Suitable-N):

4) N1 = currently not suitable

5) N2 = permanently not suitable: $<40 \%$ of maximum yield

III - Land suitability sub-classes. These indicate the type of limitations and improvements required within the classes. Limitations include soil physical constraints (s), fertility constraint (f), drainage constraint (w), and salinity/alkalinity constraint (n).

The criteria for land evaluation for rice were based on the FAO methodology for land evaluation.

\section{Results and Discussion}

In Tono Irrigation Scheme, farmers cultivate in lowlands and valley bottom locations [21] such locations are water collecting sites where substantially, more water can be available to rice plants as compared to upland situations. The Tono River, supported by the Asimsim River, drains the Scheme area.

Geologically, gneiss and granite were evident in the soils over most of the areas of the Tono Irrigation Scheme site. However, no rock outcrops were encountered along the river valleys of the Asimsim and the Tono. The parent rocks and soils derived from there are covered by old and new alluvium deposits.

The soils of the Scheme under lowlands and valley bottom sites, therefore, included Eutric Gleysol, Calsic Vertisol, Eutric Fluvisol and Eutric Plinthosol (Figure 2). These soils, generally, were heavily textured and relatively poor drained, or medium-textured and moderately to imperfectly well-drained. They showed a low to a very low rate of water percolation losses, which is good for the current farming system of cropping rice within the lowlands and valley sites of the Scheme (Figure 3).

Using soil physical properties as the main parameters and ratings adapted from [22] noted Eutric Gleysol as moderately suitable for rice, with its major limitation being loamy or silty topsoil. The Calsic Vertisol has the inherent capability of being relatively fertile and thereby suitable for rice production and cadmium accumulation in rice [23]. Its workability can be problematic and affect economic outputs. The Eutric Fluvisol soils had clear evidence of stratification and weakly developed soil horizons, but the top soil horizons were distinct. Their poor drained properties present adequate benefits for paddy rice cultivation. Also encountered intermittently was Eutric Plinthosol soil, silty to sandy clay loam $30 \mathrm{~cm}$ thick top horizon underlain by numerous iron concretions with iron pans encountered at depths of $50 \mathrm{~cm}$ or more from the surface. This group of soils was rated to be moderately suitable for rice cultivation; local farmers intensively cultivate rice on similar soils in Maranhão, Brazil [24]. However, the surface crust formation of Plinthosols can restrict water percolation, thereby hampering their management for agricultural production [24].

[22] noted the lowland and valley bottom soils evaluated in this study as major lowland rice-growing soils in the Guinea Savanna Voltaian Basin of Ghana. 
The soils are very extensive and are the primary soils for rice production in the Tono area and its environs. Because their subsoil is primarily clay, proper management, including puddling and the addition of organic matter, will considerably improve their ratings. Where the soil $\mathrm{pH}$ is less than 5.0, judicious fertilizer application and modest liming will greatly boost productivity [22].

The upland soils were generally made up of Lixisols (Haplic Lxisol and Ferric Lixisol) and Dystric Leptosol. The Lixisols were moderately well to imperfectly drained and occur on the middle to lower slopes. They had topsoil of greyish brown to light grey sandy loam, which is usually less than $30 \mathrm{~cm}$ thick. This graded into brownish yellow compact sandy clay loam below $30 \mathrm{~cm}$ and in turn overlaid several centimetres of a yellowish-brown, mottled red sandy clay loam or sandy clay. It had a relatively lower water holding capacity. Like the Lisols, Dystric Leptosol (very shallow soils over hard rock) tends to hinder rooting conditions of plants with frequent waterlogging and excessive stoniness and low chemical soil fertility. These soils are therefore not suitable for irrigated rice cultivation [15].

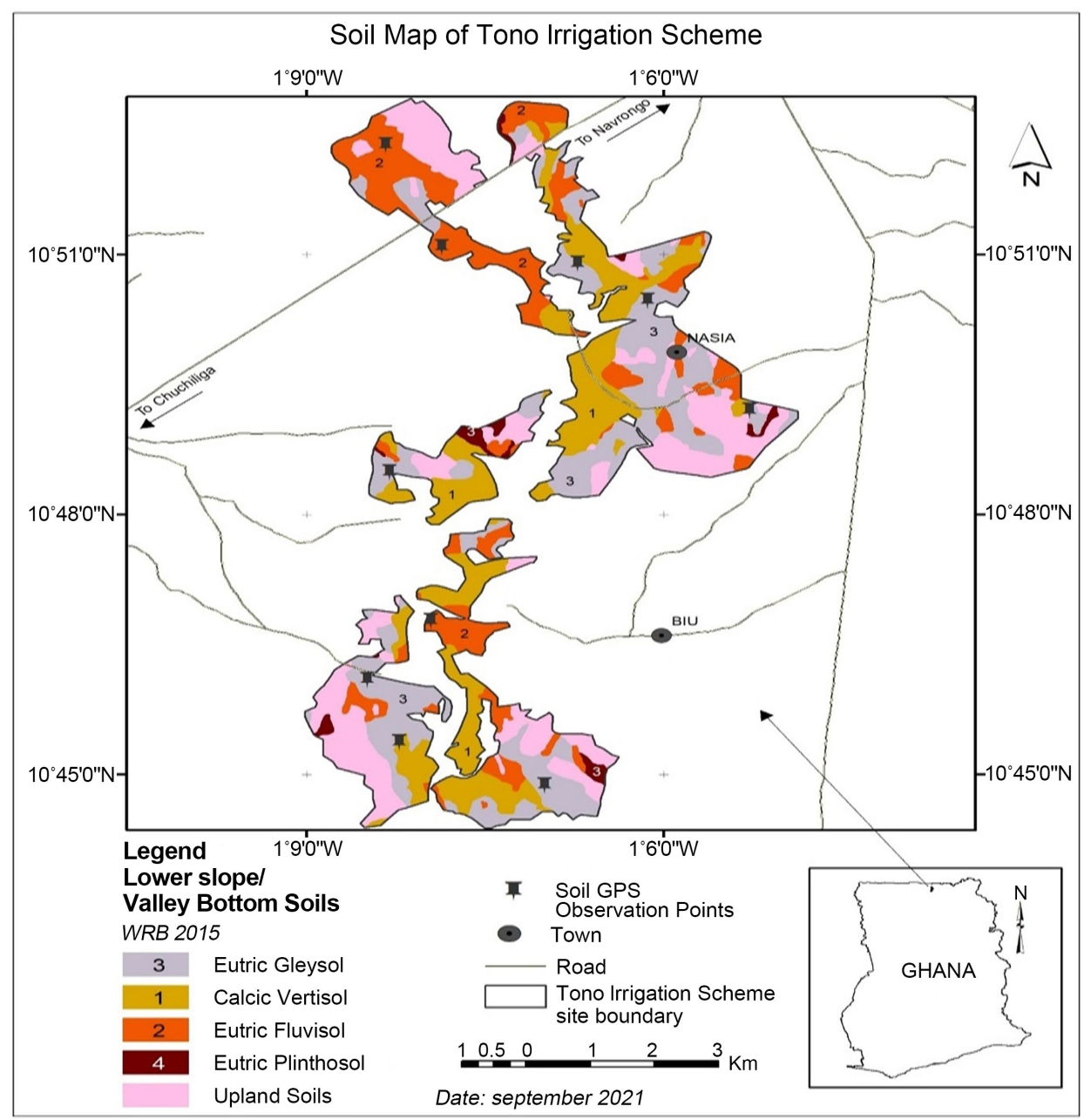

Figure 2. Soil map of tono irrigation scheme, with emphasis on the lowlands and valley bottom sites. 


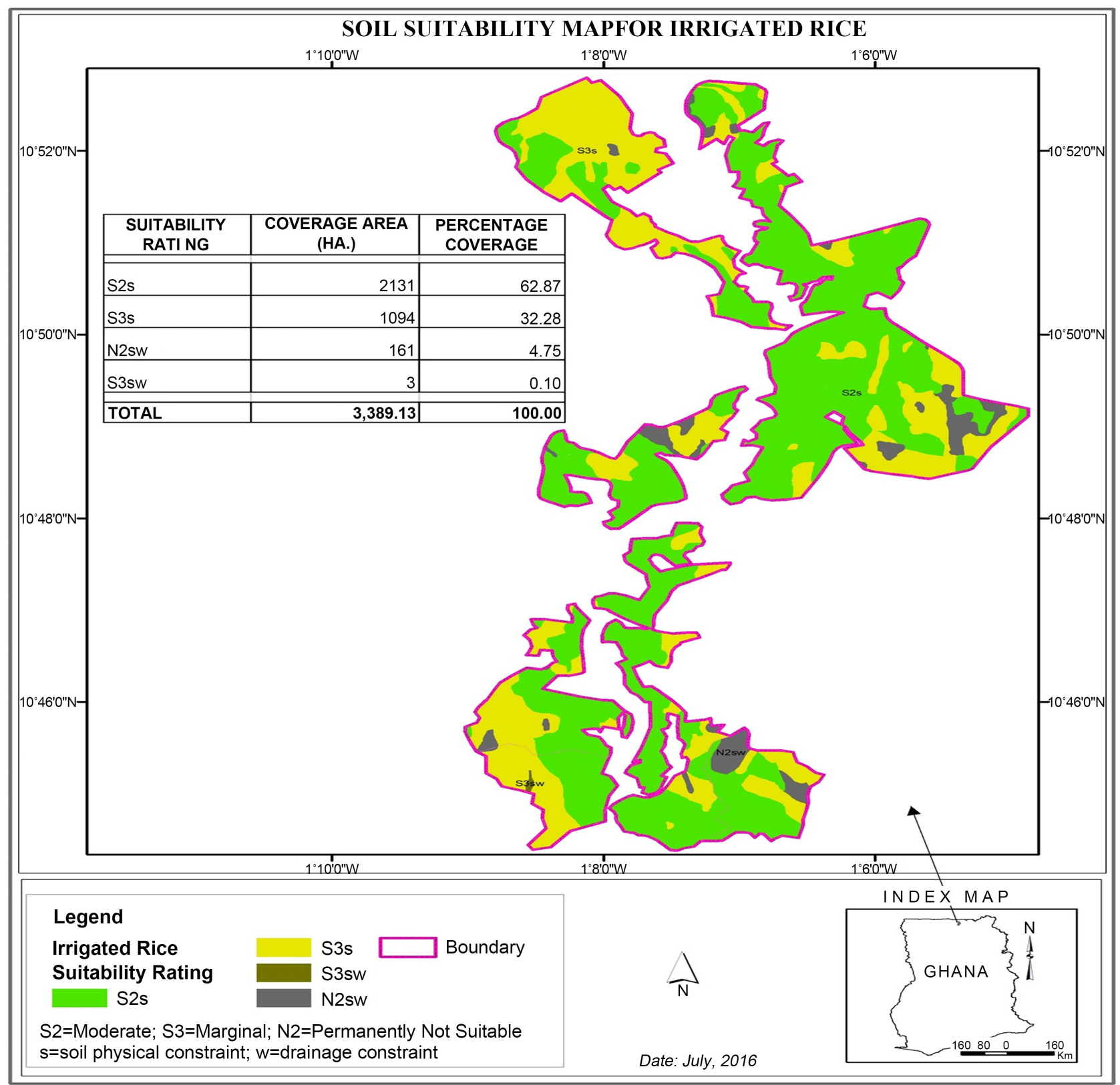

Figure 3. Soil suitability map for irrigated rice.

\section{Conclusion}

The soils were either developed directly from the parent rock or derived from colluvial and alluvial materials. They were either heavily textured or relatively poor drained or medium-textured and moderately to imperfectly well-drained. The chemical analysis indicated that the $\mathrm{pH}$ of the soils was within the acceptable range for rice crop production; however, the overall fertility level of the soils was very low. The soils were also non-saline and non-sodic. Thus, the lower to valley bottom soils (Eutric Gleysol, Calsic Vertisol, Eutric Fluvisol and Eutric Plinthosol) was inherently evaluated to be inherently moderately to marginally suitable for rice production. The upland Leptosols and Lixisols were however 
evaluated to be permanently not suitable for rice production. To achieve maximum productivity, a comprehensive soil management regime would have to be adopted by the farmers depending on the variety of rice crops to be grown. Fertilizer use (both organic and inorganic) would be key in improving the soil fertility. A major limiting factor for rice production at the site was soil texture constraint, which accounted for a moderate permeability of the soils. For rice cultivation, soil puddling is recommended in those soils to help reduce permeability and percolation losses.

\section{Acknowledgements}

We do thank the Irrigation Company of Upper Region (ICOUR) for funding the fieldwork and Mr. Enoch Boateng of Agro-Pedology.

\section{Conflicts of Interest}

The authors declare no conflicts of interest regarding the publication of this paper.

\section{References}

[1] Aondoakaa, S.C. and Agbakwuru, P.C (2012) An Assessment of Land Suitability for Rice Cultivation in Dobi, Gwagwalada Area Council, FCT. Ethiopian Journal of Environmental Studies and Management, 5, 444-451. https://doi.org/10.4314/ejesm.v5i4.S2

[2] Clacey, J.L. and Ramsay, J.M. (1954) Land Use, Soil and Water Conservation in the Northern Territories of the Gold Coast. African Soils, 3, 338-353.

[3] Adu, S.V. (1969) Soils of the Navrongo-Bawku Area, Upper Region, Ghana. CSIR-Soil Research Institute Memoir No. 5, Soil Research Institute, Kwadaso-Kumasi.

[4] Benneh, G. (1973) Water Requirements and Limitations Imposed on Agricultural Development in Northern Ghana. In: Ofori, I.M., Ed., Factors of Agricultural Growth in West Africa, Institute of Statistical, Social and Economic Research, Legon, 71-81.

[5] Anon (1983) The Northern Region, Ghana. Vol. 1, A Descriptive Overview. Report for NORRIP Technical Unit. Tamale.

[6] Blench, R.M. (1999) Agriculture and the Environment in Northeastern Ghana: A Comparison of High and Medium Population Density Areas. In: Blench, R.M., Ed., Natural Resource Management in Ghana and Its Socio-Economic Context, ODI, London, 21-43.

[7] Slaymaker, T. and Blench, R.M. (Eds.) (2002) Rethinking Natural Resource Degradation in Sub-Saharan Africa: Policies to Support Sustainable Soil Fertility Management, Soil and Water Conservation among Resource Poor Farmers in Semi-Arid Areas: Case Studies. University of Development Studies, Tamale.

[8] Lacosrep (2006) Republic of Ghana: Upper East Region land Conservation and Smallholder Rehabilitation Project (LACOSREP) - Phase II. Report for International Fund for Agricultural Development, No. 76, Lacosrep, Bolgatanga.

[9] Mganga, K.Z, Musimba, N.K.R, Nyangito, M.M, Nyariki, D.M. and Mwang'ombe, A.W. (2010) Improving Hydrological Properties of Degraded Soils in Semi-Arid Kenya. Journal of Environmental Science and Technology, 4, 217-225. https://doi.org/10.3923/jest.2010.217.225 
[10] Ahukaemere, C.M. (2018) Suitability Evaluation of Some Soils of South-Eastern Nigeria for Oil Palm (Elaeis guineensis) and Cocoa (Theobroma cacao) Cultivation. International Journal of Agriculture and Rural Development, 21, 3355-3361

[11] Olaleye, A.O., Ogunkunle, A.O., Sahrawt, K.L and Singh, B.N. (2001) Characterization of Some Benchmark Wetland Soil in Nigeria for Rice Cultivation. Communications in Soil Science and Plant Analysis, 32, 189-208.

https://doi.org/10.1081/CSS-100103002

[12] FAO (Food and Agriculture Organization of the United Nations) (1978) Effects of Compaction and Puddling on Soil Physical Properties and Rice Growth. Food and Agriculture Organization of the United Nations, Rome, 68-73.

[13] Naabil, E., Lamptey, B., Arnault, J., Olufayo, A. and Kunstmann, H. (2017) Water Resources Management Using the WRF-Hydro Modelling System: Case-Study of the Tono Dam in West Africa. Journal of Hydrology. Regional Studies, 12, 196-209. https://doi.org/10.1016/j.ejrh.2017.05.010

[14] Adams, S., Issaka, R.N., Quansah, G.W., Amfo-Out, R. and Bagna, S. (2014) Assessment of Irrigation Water Quality of Tono Dam in Navrongo, Ghana. Journal of Biodiversity and Environmental Sciences (JBES), 4, 187-195

[15] Boateng, E. (1991) Preliminary Soil Studies along the Left Bank of the White and Black Volta Rivers in the Northern, Upper East and West Regions. SRI Technical Report No. 160, Kwadaso-Kumasi.

[16] National Soil Survey Center (2002) Field Book for Describing and Sampling Soils. Version 2, Natural Resources Conservation Service, U.S. Department of Agriculture, Washington DC.

[17] Kakulu S.E (1993) Biological Monitoring of Atmospheric Trace Metal Deposition in North-Eastern Nigeria. Environmental Monitoring and Assessment, 28, 137-143. https://doi.org/10.1007/BF00547032

[18] Allison, L.E. (1960) Wet-Combustion Apparatus and Procedure for Organic and Inorganic Carbon in Soil. Soil Science Society of America Journal, 24, 36-40. https://doi.org/10.2136/sssaj1960.03615995002400010018x

[19] Ibitoye, A.A. (2006) Laboratory Manual on Basic Soil Analysis. 2nd Edition, Foladave Nig. Ltd., Akure, 32-36.

[20] FAO (Food and Agriculture Organization of the United Nations) (1985) Guidelines: Land Evaluation for Irrigated Agriculture. Soils Bulletin No. 55, Food and Agriculture Organization of the United Nations, Rome

[21] Namara, R.E., Horowitz, L., Kolavalli, S., Kranjac-Berisavljevic, G., Dawuni, B.N., Barry, B. and Giordano, M. (2010) Typology of Irrigation Systems in Ghana. Vol. 142, International Water Management Institute, Colombo.

https://doi.org/10.5337/2011.200

[22] Senayah, J., Issaka, R. and Dedzoe, C. (2008) Characteristics of Major Lowland Rice-Growing Soils in the Guinea Savanna Voltaian Basin of Ghana. Agricultural and Food Science Journal of Ghana, 7, 561-574.

https://doi.org/10.4314/afsjg.v7i1.43034

[23] Sebastian, A. and Prasad, M. (2014) Vertisol Prevents Cadmium Accumulation in Rice: Analysis by Ecophysiological Toxicity Markers. Chemosphere, 108, 85-92. https://doi.org/10.1016/j.chemosphere.2014.02.077

[24] Da Silva Martins, A.L., de Oliveira, A.P., de Moura, E.G. and Camacho-Tamayo, J.H. (2012) Surface Infiltration on Tropical Plinthosols in Maranhão, Brazil. In: Lee, T.S., Ed., Water Quality, Soil and Managing Irrigation of Crops, IntechOpen, London, 149. https://doi.org/10.5772/33292 